\title{
Republicanizar la religión: el clero en el debate político de la independencia chilena, 1808-1814
}

Republicanizing religion: the clergy in the political debate concerning Chilean Independence, 1808-1814

Gabriel CID

Universidad Diego Portales, Santiago de Chile

gabriel.cid@udp.cl

Abstract: This paper analyzes, from the perspective of intellectual history, the theological debate during the first period of Chilean independence. Focusing on the public role of religious discourse and the political dimension of the clergy's activity, this work examines the discussions related to the problem of popular sovereignty, the theory of the divine right of kings, the religious justification of political change and the attempts to promote republican ideology from a Biblical perspective.

Keywords: Independence; Religion; Republicanism; Political Theology.
Resumen: El trabajo analiza, desde la perspectiva de la historia intelectual, la discusión teológica durante la primera fase de la independencia de Chile. Centrándose en el rol público del discurso religioso y en la dimensión política del clero, el artículo examina los debates relativos al problema de la soberanía popular, el derecho divino de los reyes, la justificación religiosa del cambio político y los esfuerzos por promover el republicanismo desde una perspectiva bíblica.

Palabras clave: Independencia; Religión; Republicanismo; Teología política.

\section{INTRODUCCIÓN: LA RELIGIÓN COMO DISCURSO POLÍTICO}

Uno de los grandes factores de continuidad tras el colapso del imperio español durante la era de las revoluciones fue la religión. En medio de la vorágine de los acontecimientos que se desencadenaron con una velocidad inusitada tras los sucesos de Bayona en 1808, el catolicismo parecía ser el único elemento que despertaba un consenso transversal entre la población de la Monarquía hispánica, el único que sobreviviría a la borrasca revolucionaria de la época. Esto obedeció a una serie de factores: entre estos se encuentra su profundo arraigo en la cultura popular, la amplia presencia territorial de la Iglesia y el carácter profundamente político que adquirió el catolicismo al momento de perfilar la legitimidad del imperio español.

El catolicismo no era un elemento accesorio al funcionamiento de la Monarquía hispánica, sino constitutivo de ella, esencial a su definición, en tanto 
ésta se fundaba desde sus inicios en valores religiosos. Con el descubrimiento de América la vocación universal que adquirió su política no estaba estrictamente asociada a un proyecto imperial, sino también a cuestiones de tipo religioso: la Monarquía adquiría así un sentido de misión providencial, al asumir el rol de extender el cristianismo en los confines del Nuevo Mundo. ${ }^{1}$ Esta imbricación profunda del catolicismo en el seno de la cultura política hispánica ayuda a entender, por ejemplo, que el experimento constitucional de Cádiz sancionara el exclusivismo católico con escaso debate entre los miembros de las Cortes, pues se entendió que la religión era uno de los elementos esenciales de la cultura hispánica, cuya preservación contribuiría a paliar el riesgo de la desintegración imperial ${ }^{2}$.

Así, de forma casi inevitable las transformaciones políticas más relevantes de la época habían de ser discernidas desde el prisma religioso, no solo por su alcance social, sino también porque este proceso era propio de un período donde la política no era una esfera autónoma, ni deslindada claramente de lo religioso. Esta situación no fue privativa, en todo caso, del mundo hispánico, ya que este mismo proceso puede constatarse en el escenario estadounidense. Allí las diversas confesiones protestantes proveyeron un copioso acervo de principios morales y políticos e insumos ideológicos para la construcción de la república, impregnándola de un contenido providencial ${ }^{3}$. Del mismo modo, en el contexto revolucionario francés, incluso el jacobinismo articuló muchas de sus reflexiones políticas sobre una matriz de pensamiento cristiana, entre estas, la idea de regeneración ${ }^{4}$.

Para aprehender el rol público de la religión desde esta perspectiva es preciso transitar desde la historia del clero en clave de historia eclesiástica -corriente historiográfica dominante que ha producido una copiosa literatura para el caso chileno $^{5}$ - a una que ponga el acento más bien en su papel de dispensadores de

1 Eva BOTELla-ORDINAS, «Exempt from Time and from its Fatal Change»: Spanish Imperial Ideology, 1450-1700, en Renaissance Studies, 26 (2012/4), pp. 580-604.

2 José María Portillo ValdÉs, De la monarquía católica a la nación de católicos, en Historia y Política, 17 (2007), pp. 17-35.

3 Thomas S. KIDD, God of Liberty. A Religious History of the American Revolution, Nueva York, 2010.

4 Lucien Jaume, Le religieux et le politique dans la Révolution Française. L'idée de régénération, París, 2015.

5 Sin pretensión de exhaustividad, algunos trabajos que examinan el rol del clero desde esta perspectiva son Carlos SILva CoTAPOS, El clero chileno durante la guerra de la Independencia, Santiago, 1911; Eduardo Cavieres, La Iglesia y la Independencia de Chile, en Cuadernos de Historia, 33 (2010), pp. 37-61; Sergio VERGARA QUIROZ, Iglesia y Estado en Chile, 1750-1850, en Historia, 20 (1985), pp. 319-362; Miguel Luis AMUNÁTEGUI y Diego Barros Arana, La iglesia frente a la emancipación americana, Santiago, 1960; Luis OlIVARES MOLINA, Un curioso personaje de nuestra Independencia nacional: don Rafael Andreu y Guerrero, obispo titular de Epifanía, en Anuario de Historia 
insumos ideológicos fundamentales para construir la legitimidad de los posicionamientos políticos durante la era de las revoluciones.

Más allá del hecho de que la historiografía haya estado centrada en la dimensión institucional del clero, hay otro factor que incide en la escasa atención prestada a la teología como «materia prima» ideológica del proceso independentista chileno. Me refiero a la hegemonía que se le ha adjudicado al liberalismo en la construcción de la narrativa del período independentista. Este hecho ha llevado a la literatura a subestimar el rol de la religión, o derechamente a invisibilizarlo, lo cual no deja de ser sorprendente habida cuenta del profundo arraigo del catolicismo en la cultura política de la época. De cierta forma, las tesis liberales predominantes -Simon Collier, Alfredo Jocelyn-Holt o Ricardo Donoso, en su vertiente más militante ${ }^{6}$ - descartan implícita o explícitamente la relevancia política de la religión (salvo que juegue un papel de lastre para el progreso) entendiendo que, como la Independencia estaba inserta en un proceso de modernización ya iniciada en el siglo XVIII, en tanto era heredera de la Ilustración, su importancia política en el espacio público estaba destinada a desaparecer de antemano.

Dichas aproximaciones soslayan algo que para los contemporáneos era obvio: que lo político y lo religioso no eran esferas autónomas, no solo porque nunca lo habían sido hasta entonces, sino porque dicha autonomía era impensable en ese momento para una sociedad no secularizada, donde el catolicismo era un rasgo constitutivo de su identidad y de su cultura política. En términos ideológi-

de la Iglesia en Chile, 1 (1983), pp. 125-179; Lucrecia ENRÍQUEZ, Trayectoria política de un obispo español en la revolución americana: Diego Antonio Navarro Martín de Villodres, obispo de Concepción (1806-1816), en Anuario de Historia de la Iglesia en Chile, 23 (2005), pp. 39-57; Rigoberto ITURRIAGA, Fray fosé María Bazaguchiascúa, obispo electo de Ancud (1769-1840), en Anuario de Historia de la Iglesia en Chile, 28 (2010), pp. 81-98; Marciano BARros, José Ignacio Cienfuegos: nacionalista y patriota, en Anuario de Historia de la Iglesia, 17 (2008), pp. 179-189; Fernando Aliaga, Proyecto ético-político del clero patriota en Chile, en Anuario de Historia de la Iglesia, 17 (2008), pp. 191-203; Lucrecia ENRÍQUEZ, El clero y la independencia de Chile, en Josep-Ignasi SARANYANA y Juan Bosco AMORES (eds.), Política y religión en la independencia de la América hispana Madrid, 2011, pp. $187-$ 218; Osvaldo Walker, La orden de San Agustín y la Independencia de Chile, en Revista Chilena de Historia y Geografía, 146 (1978), pp. 281-303; Walter HANISCH, Los jesuitas y la independencia de América y especialmente de Chile, en Boletín de la Academia Chilena de la Historia, 82 (1969), pp. 13 82; Lucrecia EnríQueZ, Paula JimÉneZ y José Manuel CASTRO, La orden de Predicadores en la Independencia de Chile y en la república decimonónica, en Eugenio TORRES (coord.), Los dominicos insurgentes y realistas, de México al Río de la Plata, México, 2011, pp. 473-525; y Lucrecia ENRÍQUEZ, La orden de la Merced en la víspera de la Independencia de Chile, en María José CoT y Claudio RoLle (eds.), Letras de humanidad. Escritos en honor a Francesco Borghesi, Santiago, 2008, pp. 259-273.

6 Simon Collier, Ideas y política de la independencia chilena, 1808-1833, Santiago, 1977; Alfredo JOCELYN-HolT, La Independencia de Chile. Tradición, modernización y mito, Santiago, 2001; y Ricardo DonOso, Las ideas políticas en Chile, Santiago, 1967. 
cos, además, el contenido diferenciador en estas esferas que portaría en su lógica interna la Ilustración debe ser matizado para el caso hispánico, porque esta fue una «Ilustración católica», como la llamó Mario Góngora ${ }^{7}$.

El problema de dichas aproximaciones es, a nuestro juicio, haber asumido acríticamente la genealogía que la secularización -un «concepto de combate» surgido a mediados del siglo $\mathrm{XIX}^{8}$ - se confirió a sí misma, en una metanarrativa del triunfo de la racionalidad y la modernización, aquel proceso irreversible y de alcance global, cuyo estadio final sería la declinación de la confesionalidad religiosa hasta su agonía, una tesis que, como sabemos, está empezando a ser cuestionada en el campo de las ciencias sociales?.

La paradoja es que la religión, ese mismo factor que había permitido aunar posturas en los primeros momentos de la crisis hispánica, al inscribirse en una dinámica política de colapso de la metrópoli terminó constituyéndose en una cuña ideológica que permitía lecturas y posicionamientos políticos disímiles a medida que el proceso se desarrollaba. Este proceso fue común a todo el conjunto de la Monarquía, con opiniones que interpretaban la revolución como un pecado colectivo, o bien la justificaban teológicamente como un proyecto afín a los principios y valores del cristianismo ${ }^{10}$.

Así, las páginas que siguen buscan adentrarse en un debate inherente a todo proceso de cambio de sistema de gobierno, como el que se dio con particular intensidad en el mundo hispánico, y particularmente en Chile, entre 1808 y 1814: interrogarse primeramente respecto a si es posible cambiar el régimen político. Es decir, si los feligreses poseen dicha potestad y, en caso de respuesta afirmativa, cómo se justifica religiosamente este cambio, o cómo se llena de un sentido teológico a este proceso. En este trabajo examino el despliegue de esta doble problemática, la primera circunscrita a la elaboración religiosa de una nueva argu-

7 Mario Góngora, Estudios sobre la historia colonial de Hispanoamérica, Santiago, 1998, p. 191. Cabría añadir que esta vertiente católica de la Ilustración no es exclusiva del mundo hispánico. Cfr. Ulrich L. LEHNER y Michael PRINTY (eds.), A Companion to the Catholic Enlightenment in Europe, Leiden, 2010.

8 Ian HunTER, Secularization: the Birth of a Modern Combat Concept, en Modern Intellectual History, 12 (2015/1), pp. 1-32. El concepto se utilizaba mucho antes de ese período, pero su uso se vinculaba al lenguaje eclesiástico del derecho canónico, no para designar un proceso de diferenciación de la política y la religión.

9 La discusión al respecto es amplísima como para ser detallada. Una síntesis de estos cuestionamientos la proporciona Rodney STARK, Secularization, R.I.P., en Sociology of Religion, 60 (1999/3), pp. 249-273.

10 John LYNCH, La revolución como pecado: la Iglesia y la independencia hispanoamericana, en América Latina, entre colonia y nación, Barcelona, 2001, pp. 171-206. 
mentación en torno al poder político, en concreto, sobre la validez teológica del principio de la soberanía popular. Luego el artículo se adentra en el despliegue de argumentos relativos a la discusión sobre el cambio de régimen político, en aquel problema que sugiere el título: republicanizar a la divinidad.

\section{LOS DILEMAS DE LA SOBERANÍA EN EL DEBATE TEOLÓGICO}

El mes de agosto de 1808 estuvo signado por la ambigüedad en el Reino de Chile. La recepción de las noticias del ascenso al trono de Fernando VII fue simultánea a la de los sucesos de Bayona y la prisión de la familia real. El fidelismo, la profundización del sentimiento anti-francés, la profusión de muestras de apoyo hacia la Monarquía y la exacerbación de la identidad católica marcaron la tónica de esos momentos. El juramento de fidelidad al rey ausente que se llevó a cabo en la capital del Reino el 25 de septiembre fue un ejemplo claro de esta situación, así como lo fueron las rogativas públicas que en Concepción realizaron los religiosos franciscanos, pidiendo a la Virgen «para que interponiendo su poderosa intercesión, nos alcance el mayor bien que es la paz con total victoria de nuestros enemigos y restitución de nuestro deseado monarca» ${ }^{11}$.

Este firme posicionamiento inicial, no obstante, se mezcló con la incertidumbre que se extendía ante las noticias recibidas de la metrópoli y la dramática variación de su situación militar. La ocupación de Andalucía por la Grande Armée a fines de 1809 fue un verdadero terremoto político para la provisoria institucionalidad construida tras Bayona. En dicho escenario la Junta Suprema Central se disolvió, transfiriendo sus poderes al Consejo de Regencia en enero de 1810. Las mismas directrices que emanaron de las autoridades peninsulares contribuyeron a despertar la discusión respecto al horizonte de acción política que la acefalía real suponía para el conjunto del orbe hispánico, al señalar la igualdad de derechos entre las partes integrantes de la Monarquía y brindar en la institución juntista un modelo a seguir para los americanos ${ }^{12}$.

Así, a mediados de 1810 el problema que suscitó las discusiones fue el lugar legítimo de la soberanía y la capacidad de autogobierno que esta implicaba. Este

11 SEVILla, ARCHIVo GENERAL DE INDias, Chile, 206, carta de fray Antonio Rocamora al P. Reverendísimo de Indias, Chillán, 27 de diciembre de 1809.

12 Decreto del Consejo de Regencia, 14 de febrero de 1810, en Martha ETCHART, Documentos de Historia Americana, Buenos Aires, 1979, pp. 123-124; La Junta Superior de Cádiz a la América Española, Lima, 1810, p. 3. 
giro en los sucesos obligó al clero a transitar desde el tradicional discurso antifrancés, que insistía en el riesgo que para la pureza de la fe suponían los «impíos y libertinos» jacobinos que actuaban «atropellando las más sanas y antiguas leyes del catolicismo» ${ }^{13}$, a pronunciarse respecto a la contingencia política y al dilema central de aquellos instantes.

Este desplazamiento en la discusión religiosa se refleja claramente en la pastoral que en junio de 1810 hizo circular el obispo de Concepción, Diego Antonio Navarro Martín de Villodres. Antes de arribar al país Villodres, que era abogado y doctor por la Facultad de Cánones de la Universidad de Osuna, además de consultor del Santo Oficio, había experimentado en carne propia los avatares de la era de las revoluciones, siendo apresado por las tropas napoleónicas durante la ocupación de Córdoba en 1808. Esta experiencia sería central en la configuración del discurso que desplegaría cuando arribase, recién en 1810, al obispado al que había sido presentado cuatro años antes ${ }^{14}$. Por una parte, porque permite entender su discurso anti-revolucionario y su posicionamiento contrario a los philosophes, pero también porque era consciente de que los reveses militares sufridos en la Península, que él conocía de primera mano, podían debilitar la adhesión de los criollos hacia las instituciones representativas existentes en la metrópoli.

Por ello, una de sus primeras tareas públicas consistió en hacerles notar a sus feligreses que la lucha contra Napoleón también pasaba por mostrarse obedientes a la Junta Superior de Cádiz. Esta instancia era legítima, justamente porque algunos de sus integrantes eran americanos, encontrándose representadas así los intereses de las partes integrantes de la Monarquía. Dicha unanimidad era necesaria si se ponderaba la magnitud de la lucha, que enfrentaba a quienes buscaban «ahuyentar del mundo la moral de J. C.», representados por Francia, «centro del charlatanismo filosófico». El peligro de que el «volcán de la revolución» alcanzase los dominios americanos llevaba a Villodres a pedirle a los feligreses mayor cuidado en la observancia de la fe y emprender rogativas «por la unidad de la Iglesia, por la prosperidad de nuestras armas, por la estabilidad de la Monarquía,

13 SANTIAgO, ARCHIVO NACIONAL HISTÓRICO, Fondo Antiguo, 34, Mística Junta que se hizo en esta ciudad de Santiago de Chile a 18 del mes de julio del presente año de 810, por las más nobles y piadosas señores realistas para ratificar el juramento de obediencia, subyugación y fidelidad a la Iglesia de Dios y Real Persona de N. F. VII, pieza 23, f. 199.

14 SEVILLA, ARCHIVO GENERAL DE INDIAS, Chile, 454, Relación de los méritos, grados y exercicios literarios del doctor D. Diego Antonio Navarro Martín de Villodres; ENRÍQUEZ, Trayectoria política... [ver n. 5], pp. 39-51. 
por el acierto de las Cortes, y por la libertad y restitución a su trono de nuestro amado Fernando $7^{\circ} \gg^{15}$.

Los esfuerzos de Martín de Villodres iban en la línea de neutralizar las primeras dudas hacia la legitimidad de las instituciones peninsulares como justas depositarias de la soberanía. No obstante, en agosto de 1810 esta posición comenzó a ser cuestionada, pues se ponía en tela de juicio la supervivencia de las mismas. Pero también porque, como lo reflejan textos del momento como el Catecismo político-cristiano, el concepto de soberanía estaba siendo objeto de controversia, intentando ser reformulado en clave contractualista. En ausencia del rey, sentenciaba el manuscrito que circuló anónimamente entre julio y septiembre, «la autoridad vuelve al pueblo de donde emanó, y el pueblo es el único que tiene autoridad para nombrar o instituir un nuevo rey, o para darse la forma de gobierno que más le acomode a su prosperidad $\gg^{16}$.

El sermón que a fines de agosto predicó José María Romo en la iglesia de la Merced en la capital demuestra este cambio en el contexto de debate. El mensaje transmitía perturbación ante la creciente popularidad de lo que él denominó «espíritu revolucionario y altanero», cuya manifestación más patente era la idea de establecer en Chile una Junta de Gobierno, propuesta que consideraba contraria «a las leyes de nuestra monarquía y contra los preceptos de Dios». Para el mercedario no existía autorización desde la Península para proceder en este sentido, pues ya existía una autoridad legítima que resguardaba la soberanía del monarca, la Junta Superior de Cádiz (la Regencia). Incorporando en el debate el conocido pasaje del capítulo XIII de la Epístola a los Romanos que trata de la obediencia a las autoridades constituidas -pasaje que, en adelante, devendría en referencia bíblica ineludible-, Romo arguyó que el juntismo expresaba una resistencia a la voluntad divina, incurriendo en los pecados de infidelidad y perjurio. Así, la propuesta de instaurar una junta chilena era la expresión más visible de las aspiraciones propias de «una soberbia luciferina», que habían «degradado a nuestro reino del concepto de fiel, obediente y sumiso, en que lo han tenido las naciones». Conductas reprochables como estas, concluía el mercedario, excitarían la ira divina, facilitando «que descargue sobre nosotros todos sus rayos y anatemas» ${ }^{17}$.

15 La pastoral de Diego Antonio Navarro Martín de Villodres, fechada el 1 de junio de 1810, se reproduce en Rubén VARGAS UGARTE, El episcopado en los tiempos de la emancipación sudamericana, Buenos Aires, 1945, pp. 346-361.

16 José AMOR DE la PaTRIA, Catecismo político cristiano, Buenos Aires, 1969, pp. 21-22.

17 Sermón pronunciado por el R. P. fray José María Romo en la Iglesia de la Merced el 29 de agosto de 1810, en Colección de Historiadores y de documentos relativos a la Independencia de Chile, Santiago, 19001966 , t. 18 , pp. 105-108. 
La politización del discurso religioso comenzaba así a plantear dificultades a quienes defendían la retroversión de la soberanía y la capacidad de autogobierno criollo. Eso permite entender no solo la censura que el Cabildo de Santiago realizó contra el sermón de Romo, sino también la sugerencia que elevó al Presidente del Reino para prohibir al clero pronunciarse sobre este tipo de problemas, requiriendo la censura previa de los sermones ${ }^{18}$.

En septiembre de 1810 se procedió finalmente a la formación de la Junta de Gobierno chilena, instancia que materializó los discursos en torno al lugar de la soberanía. Como era de esperarse, la Junta requirió justificar teológicamente su misma existencia, misión que cumplió el presbítero Antonio Guerrero. La derrota militar de España -cuya existencia soberana se reducía básicamente a la ciudad de Cádiz- hacía suponer que la amenaza napoleónica cruzaría el Atlántico. En este escenario, el dominico defendió la necesidad de radicar la soberanía en América, pues permitiría conservar de mejor manera la seguridad del Reino ante una eventual invasión y asegurar la fe contra las nocivas influencias ideológicas venidas de Francia. De acuerdo al diagnóstico de Guerrero, tributario de las aprehensiones anti-filosóficas comunes al clero en aquel momento, si el Reino sucumbiese frente a una invasión francesa, «a la pureza del Evangelio sucederá el materialismo, la incredulidad y el libertinaje; así como a las leyes suavísimas del reino las extravagancias y el capricho» ${ }^{19}$.

La instalación de la Junta de Gobierno chilena fue la respuesta política a la conceptualización de la soberanía como una cualidad en depósito de los pueblos, en tutela mientras durase la vacatio regis. Sin embargo, el hecho de que una de las primeras medidas dictadas por la Junta fuese la convocatoria de un Congreso, abriendo así el debate constitucional, da cuenta de una reconceptualización del concepto de soberanía manejado por los autores, desplazándose desde su condición temporaria para pasar a ser comprendido como una atribución inherente a los cuerpos políticos, un derecho natural que abría la posibilidad de ejercer la potestad legislativa ${ }^{20}$.

18 Queja del Cabildo ante el Presidente por las expresiones vertidas por el padre Romo en su sermón, 31 de agosto de 1810, en Colección... [ver n. 17], t. 18, pp. 108-112.

19 Sermón de acción de gracias, por la instalación de la Excma. Funta Gubernativa, dicho en la Catedral de Santiago de Chile el 11 de octubre de 1810, por fr. Antonio Guerrero, en Colección... [ver n. 17], t. 18, p. 349.

20 Noemí Goldman, Soberanía en Iberoamérica. Dimensiones y dilemas de un concepto político fundamental, 1780-1870, en Javier FERNÁNDEZ SEBASTIán (dir.), Diccionario político y social del mundo iberoamericano, Madrid, 2009-2014, t. 2, v. 10, pp. 23-26. 
El clérigo que justificó esta transición fue Camilo Henríquez, a quien se le encargó el discurso inaugural del Congreso Nacional en julio de 1811. El fraile de la Buena Muerte, detenido en 1809 por la Inquisición ante la sospecha de estar en contacto con literatura prohibida y testigo de los sucesos de Quito ese mismo año ${ }^{21}$, defendió la reunión del cuerpo representativo como el fruto de las circunstancias excepcionales que afectaban a la Monarquía hispánica. Para el fraile valdiviano, tanto «la doctrina de la religión católica» como «la equidad natural» conferían «eternos e inalienables derechos» a «todos los pueblos del mundo». Esta declaración servía como base para lo que probablemente fue su tesis más sugerente: la perspectiva constructivista que poseía de las comunidades políticas. Las circunstancias habían variado tan radicalmente la situación de la Península, que habían empujado a la formación de una nueva comunidad que, debido tanto a su lejanía de la metrópoli como a su aislamiento territorial, podía autodenominarse como una «nación».

El estatuto de «nación» que Henríquez le asignaba a Chile era central, toda vez que le permitía arrogarse una serie de derechos sancionados por la Divinidad, como «la facultad de defender y sostener la libertad de nuestra nación, la permanencia de la religión de nuestros padres y las propiedades y el honor de nuestras familias». En este caso, la reasunción de la soberanía era un procedimiento legítimo tanto desde el punto de vista político como religioso, en tanto permitía garantizar de mejor modo esta serie de derechos. Por esto, señalaba, la «nación» chilena podía también ejercer la potestad legislativa y sancionar una Constitución «que rija el estado en ausencia del rey». La conclusión de Henríquez era justamente aquella que deseaban oír los criollos autonomistas: que «la religión católica, que no está en contradicción con la política, autoriza a nuestro Congreso Nacional para establecer una Constitución $»^{22}$.

Este posicionamiento teológico tensionó las posturas políticas del clero en el país, al punto de dividirlas. La serie de lineamientos que los provinciales de la Merced y de Santo Domingo dirigieron a sus miembros dan cuenta de que la politización de la religión no solo se expresaba en el debate público, sino también en el espacio del confesionario y del púlpito, impactando las opiniones de los feligreses. Así, prohibieron bajo pena de excomunión utilizar estos espacios para oponerse al proyecto autonomista de los criollos, incentivando, por el contrario,

21 Miguel Luis Amunátegui, Camilo Henríquez, Santiago, 1889.

22 Sermón predicado por Camilo Henríquez el día de la apertura del Congreso, en Valentín LeTELIER, Sesiones de los Cuerpos Lejislativos de la República de Chile, 1811 a 1845, Santiago, 1887-1908, t. 1, pp. 34-36. 
la prédica a su favor. El mercedario Joaquín de Jaraquemada señaló que la legitimidad de las autoridades chilenas radicaba en que permitía de mejor forma el mantenimiento de la integridad de las posesiones de la Corona ante el riesgo de la «dominación extranjera, que infaliblemente traerá a nuestro religioso suelo el pestilente veneno de la herejía $\gg^{23}$. Por su parte, el dominico Domingo Velasco llamó a sus feligreses a no escuchar a quienes buscaban «prostituir las palabras del Señor con malignas intenciones», entre ellas, negar obediencia a las nuevas autoridades ${ }^{24}$.

\section{CATOLICISMO, RÉGIMEN DE GOBIERNO Y DESACRALIZACIÓN DE LA MONARQUÍA}

El deslizamiento de los lenguajes políticos desde el fidelismo de 1808 hasta la defensa de la retroversión de la soberanía y la potestad constituyente del pueblo chileno hacia 1811 reformularon el contexto de debate, llevándolo hacia la discusión en torno al tipo de gobierno que se conformaría en el futuro. El ascenso al poder de José Miguel Carrera supuso la radicalización del proceso de autonomía respecto a la metrópoli. El despliegue simbólico que subrayaba la vocación de constituir una comunidad política distinta, el surgimiento de la prensa como instancia de socialización del discurso autonomista, y las propuestas de constitucionalizar la autonomía chilena que iban en un sentido opuesto al proceso gaditano, despertando los recelos de las autoridades virreinales en Lima, son aspectos que denotan este cambio en el proceso político. Es lo que Bragoni llama «el giro carrerino a la revolución chilena» ${ }^{25}$.

La posibilidad de que el proceso constitucional desembocase en un texto de carácter republicano suponía un desafío político e intelectual importante para los defensores de la vía autonomista chilena. En términos religiosos, porque esto implicaba desarticular aquel vínculo de tintes casi esencialistas que se había forjado entre catolicismo y monarquía, relación que no solo tenía a su favor el peso abrumador de la historia a sus espaldas, sino también porque había sido canoni-

23 Circular del provincial de la Merced a los relijiosos de su orden, en Valentín LETELIER, Sesiones... [ver n. 22], t. 1, pp. 89-90.

24 Circular del provincial de Santo Domingo a los relijiosos de su orden, en Valentín LETELIER, Sesiones... [ver n. 22], t. 1, p. 94.

25 Beatriz BRAgOni, José Miguel Carrera. Un revolucionario chileno en el Río de la Plata, Buenos Aires, 2012, pp. 69-114. 
zada teóricamente a mediados del siglo XVIII por Montesquieu, con su aforismo: «La religión católica es más propia de una monarquía, la protestante se acomoda mejor a una república» ${ }^{26}$.

Pronunciarse respecto a la valoración que el catolicismo tenía respecto a los diferentes regímenes políticos fue el propósito con el cual Agustín Vial y Camilo Henríquez publicaron, en el primer periódico nacional, sus reflexiones políticoteológicas. Para Vial era necesario enfatizar que el catolicismo, contrariamente a lo que esgrimían sus críticos, no era contrario a la libertad, sino que esta «es amiga verdadera de la religión de Jesucristo». De acuerdo al diputado por Valparaíso en el Congreso de 1811, «todo sistema liberal, regulado por los sanos principios de la libertad civil», gozaba del apoyo de la religión, que condenaba no a esta, sino «el desorden, la tiranía, el despotismo y la injusta servidumbre». Lo fundamental, en esta línea, era la equivalencia de fondo de todos los regímenes respecto a la religión: esta podía asegurar «felicidad o desgracia» de los pueblos tanto en una república como en una monarquía ${ }^{27}$.

Días después, Camilo Henríquez, el editor de la Aurora, entró al debate para apoyar la postura de Vidal. Insistiendo en la falsedad de la supuesta unión natural que existiría entre catolicismo y monarquismo, el fraile reformuló el marco de la discusión subrayando la compatibilidad profunda que existiría entre la libertad política y la religión. Si bien existía una nutrida literatura que denunciaba a la religión católica como «enemiga de la libertad pública», existiendo así un «complot sacrílego entre el cielo y la tierra, entre el altar y las altas potestades», Henríquez llamó a desestimar esas afirmaciones y a recordar que, por el contrario, la religión nunca «aprobó el despotismo, ni bendijo las cadenas de la servidumbre». Dios mismo, como «juez integérrimo e inflexible entre los imperios y las repúblicas, miró con igual complacencia estas dos formas de gobierno» ${ }^{28}$. Lo relevante aquí es que si bien el religioso no explicitó alguna predilección religiosa por uno u otro sistema político, sí ubicó en un plano de igualdad teológica los diversos regímenes de gobierno, abriendo la opción de pensar una nueva relación entre catolicismo y constitución.

De hecho, en octubre de 1812 se sancionaba el Reglamento constitucional provisorio, en que se consolidaba el proceso de autonomía del Reino de Chile dentro del marco de una eventual monarquía constitucional, pero de impronta distinta al

26 Charles Louis de Secondat, Barón de MonTESQuIEU, El espíritu de las leyes, libro XXIV, cap. 5.

27 Agustín Vial, Pensamiento político religioso remitido al editor, en Aurora de Chile, 2 de abril de 1812.

28 Camilo HenríqueZ, De la religión católica considerada con respecto a los cuerpos políticos, en Aurora de Chile, 16 de abril de 1812 . 
modelo que paralelamente se dictaba en Cádiz. Así como en ocasiones anteriores el clero suministró la justificación religiosa para un proceso como la retroversión de la soberanía, el autogobierno y la potestad constituyente, también en este punto los religiosos se vieron obligados a intervenir en la discusión pública. Aquí, el aporte más significativo fue el de José María Bazaguchiascúa. Para este fraile franciscano oriundo de San Juan, y que se había desempeñado como maestro de latín en la Academia de San Luis y posteriormente en el Instituto Nacional ${ }^{29}$, el Reglamento era la decantación institucional de una serie de procesos políticos desarrollados tras 1810, que se resumirían en el principio de soberanía popular, la capacidad constituyente del pueblo chileno y la defensa de su autonomía política. Esos elementos, agregaba, conformaban aquello que llamó el «sistema de la patria». Este se erigía como el único régimen legítimo y que, por tanto, podía revestirse ante los feligreses chilenos de una justificación de orden divino.

Cual «innovador ideológico»-es decir, aquel que según Skinner legitima por medio de un ejercicio retórico una posición socialmente cuestionable ${ }^{30}-$, el franciscano recogió el pasaje mencionado de la Epístola de San Pablo a los Romanos relativo a la obediencia a las autoridades legítimas, un pasaje tradicionalmente utilizado para anatemizar a los opositores de la monarquía, y lo reconvirtió para asignarle dicho estatus al régimen autonomista liderado por José Miguel Carrera. $\mathrm{El}$ «sistema de la patria» debía ser obedecido justamente porque se asentaba en la existencia de elementos coherentes con el espíritu del cristianismo, tales como la preeminencia de la soberanía popular, la defensa de la libertad civil, la elegibilidad de las autoridades, la igualdad ante la ley y la fraternidad como forma de relacionarse en la polis. La confluencia de tales elementos en la teoría política que sustentaba el nuevo orden político permitía a Bazaguchiascúa declarar que «nuestro sistema es el más conexo con el del cielo», pues era «el que analogiza más con estos preceptos del Decálogo» ${ }^{31}$.

Este tipo de reflexiones teológicas y sus evidentes consecuencias políticas no pasaron inadvertidas para quienes se encontraban en las antípodas del campo político. A inicios de 1813 el texto de Bazaguchiascúa se conoció en Lima, donde

29 Rigoberto ItUrRIAGA, Fray fosé $M^{a}$ Bazaguchiascúa... [ver n. 5], pp. 81-98.

30 Quentin SKINNER, Moral principles and social change, en Quentin SKINNER (ed.), Visions of Politics: Vol.1: Regarding Method, Cambridge, 2002, p. 148

31 José María BAZAGUCHIASCÚA, «Discurso político-moral sobre que peca mortalmente todo el que no sigue el sistema de la Patria, y respeta igualmente a las autoridades constituidas, deducidas del texto y contexto de todo el capítulo 13 de la epístola a los Romanos del apóstol San Pablo», en Aurora de Chile, 26 de noviembre de 1812. 
se observaba con preocupación el curso que seguía el proceso chileno. Allí el escrito del franciscano fue criticado por un autor anónimo que sintomáticamente se identificaba como «el ortodoxo», que acusó a los chilenos de ser unos «sacrílegos parricidas, que habéis profanado la religión del juramento, rompiendo los sagrados lazos de la fidelidad que debéis a vuestro rey, el ungido del Señor». Las autoridades chilenas no podían ser legítimas, precisamente porque el presupuesto de su existencia, el principio de la soberanía popular le confería una «autoridad de farsa», a diferencia del único y verdadero poder legítimo, aquel que provenía de Dios. Por eso, quienes suponían a la luz de la epístola paulina que el gobierno chileno era legítimo, incurrían en el pecado mortal de obedecer a autoridades sediciosas. Las autoridades legítimas eran las peninsulares, especialmente porque mediante el proceso gaditano habían logrado brindar a los habitantes de la Monarquía «una constitución, fruto de la más profunda filosofía, que asegura nuestros derechos, y nos hace la nación más libre que conoce el globo». Por eso el argumento de Bazaguchiascúa contrario a la monarquía era erróneo, fruto de una interpretación bíblica dominada «por un carácter falaz y artificioso», que en el fondo buscaba «destruir la religión con la misma religión» ${ }^{32}$.

Los pensamientos de José María Bazaguchiascúa sentaron las bases sobre las cuales se construirán en adelante los aportes que en Chile constituirán lo que Juan Bosco Amores llamó la «teología de la independencia» ${ }^{33}$, aquel discurso político-religioso que, como hemos examinado, fue articulado sobre la marcha de la radicalización del proceso autonomista. El mismo fue profundizado con el comienzo del momento bélico de la revolución, desatado cuando a inicios de 1813 arribó a Chile la expedición que, comandada por el brigadier Antonio Pareja, había despachado el virrey de Lima José Fernando de Abascal para detener el avance de lo que para él ya era un proceso abiertamente secesionista.

La apertura del momento bélico de la revolución evidentemente influyó tanto en la forma de articular los discursos religiosos como en los tópicos que concentrarían la atención. Si teóricamente la religión autorizaba el cambio del régimen político ¿cuál era el sistema de gobierno más acorde a los preceptos bíblicos, la tradición patrística, eclesiástica y pontificia? Más allá de un ejercicio teológico, dar respuestas a estas interrogantes e inclinar la balanza divina

32 ANÓNImO, Breves consideraciones sobre el discurso político moral de la Aurora de Chile, n. 42, Lima, 1813.

33 Juan Bosco Amores, En defensa del rey, de la patria y de la verdadera religión: el clero en el proceso de Independencia de Hispanoamérica, en ID. (ed.), Las independencias iberoamericanas: ¿̨un proceso imaginado?, Bilbao, 2009, p. 222. 
hacia el lado de los revolucionarios representaba un paso capital para generar adhesiones en el seno de una sociedad profundamente cristianizada, y donde la necesidad de la movilización militar revestía a este problema de un sentido de urgencia.

Por eso, el esfuerzo político-religioso del bando revolucionario se plasmó en una dimensión que, además de teórica, era necesariamente práctica. El mismo gobierno de José Miguel Carrera dispuso cambios radicales en la jerarquía eclesiástica. Así, el obispo José Santiago Rodríguez Zorrilla, quien se había negado a jurar obediencia al Reglamento constitucional, fue depuesto de su cargo y se le confinó a Colina ${ }^{34}$. En su reemplazo fue colocado el oriundo de Algeciras (Cádiz) Rafael Andreu, obispo de Epifanía, más afín a su proyecto político ${ }^{35}$. Andreu desplegó durante aquel año una intensa actividad, dentro de las cuales destaca el mandato para que los curas realizasen rogativas públicas «en que se implore el poder del Dios de las batallas en obsequio de las arenas que defienden la santa libertad de que es el Soberano Autor» ${ }^{36}$.

A la par de la dificultad que se advertía en el plano eclesiástico, en términos intelectuales los desafíos eran mayores. No solo porque las interrogantes que se abrían resultaban inéditas tanto para el caso chileno como para el conjunto del mundo hispánico, sino porque esta misma situación suponía una desventaja clave al momento de discutir la validez teológica del cambio político. En efecto, los revolucionarios debían hacer frente a la inercia de las costumbres y al peso de la tradición histórica asentada por siglos en la monarquía hispánica, donde la relación entre trono y altar parecía indisoluble, un capital político que en estos momentos desplegó todo su potencial. Francisco Antonio Pinto, quien posteriormente llegaría a ser Presidente de la República, recordó cómo era la instrucción recibida por los criollos en los prolegómenos de la revolución:

La autoridad de los reyes sobre sus súbditos emanaba del cielo, y resistirla, era rebelarse contra Dios. Tal fue el armazón de nuestra ética, y tan persuadidos quedamos de la verdad de estas doctrinas, que hubiéramos compadecido y también aborrecido como un alma réproba al desgraciado que se hubiera separado de ellas ${ }^{37}$.

34 Carlos Silva Cotapos, Don Fosé Santiago Rodríguez Zorrilla: obispo de Santiago de Chile (17521832), Santiago, 1915, pp. 111-113.

35 Luis Olivares Molina, Un curioso personaje... [ver n. 5], pp. 125-179.

36 El Monitor Araucano, 17 de abril de 1813.

37 Francisco Antonio PINTO, Apuntes autobiográficos del general don Francisco Antonio Pinto, en Boletín de la Academia Chilena de la Historia, 17 (1941), p. 70. 
Justamente hacia ese aspecto del sustento teológico del monarquismo dirigieron primero sus esfuerzos los ideólogos de la revolución: desacralizar el origen de la monarquía. De hecho, ese fue uno de los aspectos que explícitamente abordó Camilo Henríquez en su Catecismo de los patriotas, donde señaló que ningún hombre había sido rey por derecho divino: «Todos los hombres nacen iguales. El pobre y el rico fueron hechos de un mismo barro», agregando que por esto se podía afirmar que solo gobernaban legítimamente «aquellos a quienes los pueblos libres por naturaleza se habrán sujetado por libre y común consentimiento» ${ }^{38}$.

Desde un lugar teórico distinto, aunque arribaba a la misma conclusión, el guatemalteco Antonio José de Irisarri, editor del Semanario Republicano, señaló que era falso afirmar que el poder de los reyes tenía un origen divino. Mas bien, los orígenes de este régimen podían rastrearse en un pacto contractual de raíz hobbesiana: «La mayor parte de los reyes salieron del seno de la anarquía que devoraba los pueblos; otros se hicieron tales abusando de la confianza y de la inocencia de sus conciudadanos; y otros también fueron constituidos en esta dignidad por la barbarie, que reinaba antes que ellos en algunas poblaciones», aclaraba el publicista ${ }^{39}$.

El sacerdote Rafael Andreu le dio a este argumento un mayor sustento teológico. Haciendo un recorrido por la historia bíblica, el obispo de Epifanía expuso el calamitoso estado que siguió a la caída del hombre desde Adán y Eva. Tras su expulsión del paraíso, la humanidad había vivido sin regulaciones políticas y en continuas disensiones, y motivados por la codicia comenzaron a guerrear unos con otros. Pero convenciéndose, agregaba «que si cada uno iba de por sí a pelear sin uno que los gobernase, habían de ser perdidos», «por una razón natural escogieron entre todos uno a quien se sujetaron, obedecieron sus órdenes». Tal era el origen del poder de los caudillos, el imperio de la fuerza y la coerción, líderes que con el paso del tiempo «se fueron ensoberbeciendo cada día más y buscando ellos su propia gloria, fueron engrandeciendo su poder, hasta el grado de sujetar a los hombres libres a que fuesen sus esclavos, llamándose príncipe, rey y emperador» ${ }^{40}$.

Dicha perspectiva, por cierto, fue duramente rebatida por el clero realista. La activa comunidad franciscana de Chillán, que se constituyó en un verdadero

38 Camilo Henríquez, Catecismo de los patriotas, en El Monitor Araucano, 7 de diciembre de 1813.

39 Antonio José de IRISARRI, Sobre el origen y la naturaleza de las monarquías, en El Semanario Republicano, 11 de septiembre de 1813.

40 Parte del texto de la pastoral de Rafael Andreu y Guerrero es reproducida en el documento Contestación que el Colegio de misioneros de Chillán dio a la proclama que bizo circular el Ilmo. señor Obispo de Epifanía en Chillán y la frontera, en Colección... [ver n. 17], t. 22, pp. 338-339. 
bastión de resistencia monárquica en el sur del país ${ }^{41}$, salió al paso de este tipo de argumentaciones que, con sus palabras, incitaban a que las «almas cristianas se unan a unos insurgentes libertinos, impíos y sin religión $\gg^{42}$. La perspectiva teológica de los franciscanos estaba en las antípodas de la tesis hobbesiana defendida por Irisarri y Andreu, señalando que «los reyes dimanan, no de las pasiones, sino inmediatamente de Dios, para sujetar las pasiones de los hombres». Y para potenciar el argumento citaron las Sagradas Escrituras: «Por mí reinan los reyes: con mi luz, los legisladores establecen leyes justas: por mí mandan los príncipes y los poderosos deslindan la justicia» (Proverbios 8, 15). Era solo una de las referencias, pues invocando los libros del Éxodo, Samuel, los Reyes, así como de San Pablo y San Pedro, también se podía arribar a conclusiones similares: el derecho divino de los reyes ${ }^{43}$.

\section{III. «EL CIELO SE HA DECLARADO A FAVOR DEL SISTEMA REPUBLICANO»}

La desacralización del poder real fue el primer objetivo de la teología política de la independencia, pero no el último. En realidad, era la precondición teórica para llevar la discusión hacia el problema central de la relación entre catolicismo y política en aquel punto de la revolución: explicar qué régimen de gobierno era el más acorde a los preceptos divinos y la tradición bíblica. Así, los esfuerzos del clero y de los propagandistas del independentismo buscaron proporcionarle mayor densidad a la tesis que, como vimos, en noviembre de 1812 planteó Bazaguchiascúa, la idea de que «nuestro sistema es el más conexo con el del Cielo». En ese sentido, la apuesta fue más radical que criticar teológicamente al régimen monárquico: el desafío era republicanizar la divinidad.

Pese a que este fue un argumento que se instaló con fuerza a fines de 1812, ya existían antecedentes previos que habían respaldado al republicanismo fundándose en la autoridad de las Escrituras ${ }^{44}$. En el Catecismo político-cristiano, por ejemplo, tras describir tipológicamente los regímenes de gobierno -monarquía, régimen despótico y república- se señalaba que una lectura atenta del

41 Jaime VALENZUELA, Los franciscanos de Chillán y la Independencia: avatares de una comunidad monarquista, en Historia, 38 (2005/1), pp. 113-158.

42 Contestación que el Colegio de Misioneros... [ver n. 40], p. 326.

43 Ibid., p. 344, la cita es de Pr. 8, 15.

44 Aunque no tuvo repercusión en la época ni pasó más allá del plano anecdótico, resulta interesante que este argumento ya estuviese circulando en el escenario chileno a fines del siglo XVIII, como lo refleja el caso examinado por Jorge CÁCERES, Republicanismo biblico independentista. El caso de la 'Instrucción' de Antonio Berney (Santiago, 1780-1781), en Revista de Humanidades, 36 (2017), pp. 69-96. 
capítulo octavo del primer libro de Samuel permitía constatar que Dios había reprobado la monarquía «por las fundadas y sólidas razones que allí expuso su infinita sabiduría, cuya verdad nos ha hecho conocer la experiencia de todos los siglos muy a pesar nuestro, y de todos los mortales». El anónimo autor del manuscrito -que la historiografía ha querido identificar con autores tan variados como Juan Martínez de Rozas, Antonio José de Irisarri, Bernardo de Vera y Pintado y Jaime Zudáñez- dirigía sus ataques especialmente a la monarquía absoluta, porque en ella «los reyes miran y tratan a los demás hombres, sus iguales, como una propiedad que les pertenece; dicen que su autoridad la tienen de Dios, y no de ellos, y que a nadie sino a Dios deben responder de su conducta». Esto estaba en las antípodas del gobierno republicano, por quien el autor mostraba sus simpatías, pues este régimen «es el que más se acerca, y el que menos aparta a los hombres de la primitiva igualdad en que los ha creado el Dios Omnipotente» ${ }^{45}$.

El primer autor que defendió en medio de la guerra la identificación del catolicismo con el republicanismo fue Bernardo de Vera y Pintado ${ }^{46}$. Para el abogado santafesino, no había nada más lejos de la realidad que afirmar que la revolución independentista desembocaría en la herejía. Por el contrario, el republicanismo, aquella ideología política que estaba en el fondo del proceso emancipatorio, era el sistema político más afín a los preceptos evangélicos, como la igualdad natural. Y agregaba:

La religión nada tiene contra el sistema republicano que seguimos, y ella se acomoda a toda especie de Gobiernos. Cuando Jesucristo vino al mundo ¿Mandó acaso que sólo se obedeciese a los reyes, y no a los magistrados populares? Antes, si bien se reflexiona, señor mío, ningún sistema es más análogo al sagrado Evangelio que el de juntas electas por el pueblo.

Como sostenía el santafesino, en el régimen republicano «reina la igualdad, todos tienen derecho a los empleos honoríficos como sean de talento; no se conceden sólo los honores a los que tienen sus genealogías en ejecutorias y pergaminos viejos, sino el mérito personal». «Vea Ud. aquí pintado el Evangelio, y nada más», concluía ${ }^{47}$.

Queda en evidencia que la exégesis bíblica resultó clave en la conformación de este tipo de argumentos. Como ha explicado François-Xavier Guerra, las Sagra-

45 José Amor de la Patria, Catecismo... [ver n. 16], p. 8.

46 Domingo Amunátegui Solar, Don Bernardo de Vera y Pintado, Buenos Aires, 1932.

47 Bernardo de VERA Y PINTADO, Señor editor, en El Monitor Araucano, 31 de agosto de 1813. 
das Escrituras nutrieron la reflexión política durante las revoluciones hispánicas, proporcionando un caudal amplísimo de información que iba mucho más allá de la órbita teológica, pues también otorgaba una cantera de argumentos de autoridad, de modelos políticos -donde Israel, el «pueblo escogido» de Dios representaba el ejemplo por excelencia de la dimensión religiosa del orden político-, de metáforas, alegorías morales y personajes ampliamente reconocibles por el público por formar parte del acervo cultural de un mundo fuertemente cristianizado ${ }^{48}$.

Esta utilización política de la Biblia quedó ejemplificada en el texto que publicaron en conjunto los sacerdotes Pedro Arce y Camilo Henríquez, donde se propusieron hacer una «apología del cristianismo con respecto a la política». El argumento central era poner en evidencia la preferencia divina por el republicanismo, en tanto era un régimen que sustentaba de manera más adecuada algunos principios claves de la doctrina evangélica, en especial, la defensa de la igualdad y de la libertad. Citando las palabras de Jesucristo cuando afirmó a sus apóstoles que aunque los gobernantes ejercieran potestad sobre los pueblos, entre ellos las relaciones debían ser distintas - «el que quiera hacerse grande entre vosotros, será vuestro servidor ${ }^{49}-$ señalaban que con estas palabras Cristo sancionaba su preferencia por el «sistema popular», aquel «plan gubernativo» que descansaba «sobre las bases de la igualdad y fraternidad». Por eso, si era evidente que «por la voluntad de Dios» eran «iguales todos los hombres», se colegía que «ninguno puede justa y legítimamente mandar a sus iguales y hermanos, si no es elegido libremente por ellos» ${ }^{50}$. De ahí que los frailes concluyeran:

Los Gobiernos populares son los más conformes a la amabilísima doctrina del Evangelio, como que tiene por base a la igualdad y fraternidad. Igualdad, todos somos iguales a los ojos de Dios, y de la razón. Fraternidad: que feliz será, el mundo cuando todos conozcamos que somos hermanos, y nos tratemos como tales ${ }^{51}$.

48 François-Xavier GUERRA, «Políticas sacadas de las Sagradas Escrituras». La referencia a la Biblia en el debate político (siglos XVII a XIX), en Mónica QUIJADA y Jesús BUSTAMANTE (eds.), Élites intelectuales y modelos colectivos. Mundo ibérico (siglos XVI-XIX), Madrid, 2002, pp. 155-198. Véanse también los estudios de caso de Roberto DI STEFANO, Lecturas políticas de la Biblia en la revolución rioplatense (1810-1835), en Anuario de Historia de la Iglesia, 12 (2003), pp. 201-224; y Viviana ARCE, La Biblia como fuente de reflexión política en los sermones neogranadinos, 1808-1821, en Estudios sobre Historia y Cultura, 9 (2012), pp. 273-308.

49 Mc. 10, 42-45

50 Pedro ARCE y Camilo Henríquez, Artículo comunicado, en El Monitor Araucano, 19 de octubre de 1813.

51 Pedro ARCE y Camilo HenríQueZ, Concluye el discurso del núm. 82, en El Monitor Araucano, 23 de octubre de 1813 . 
La defensa del republicanismo mediante el uso de las Sagradas Escrituras no solo se fundó en establecer vinculaciones entre principios afines a la doctrina evangélica, sino que también podía articularse en base a la misma historia del pueblo de Israel. Aquí el uso político del caso de la «república de los hebreos» resultó central. En primer lugar, porque permitía ampliar la estrecha panoplia histórica de experiencias republicanas a imitar, como los modelos griego, romano, suizo, las repúblicas italianas medievales, o los Estados Unidos en un período más reciente, constituyéndose esta escasez de referentes en una de las dificultades para conformar un discurso republicano históricamente atractivo. No solo por eso la experiencia de la «república de los hebreos», el gobierno colegiado mediante jueces existente antes que los judíos pidiesen como rey a Saúl, resultaba fundamental, sino también porque permitía colegir en base la experiencia del «pueblo escogido» las preferencias divinas respecto a los regímenes políticos. De larga data en el imaginario político moderno, en tanto había sido utilizado por los republicanos británicos del siglo XVII y en la revolución norteamericana -cuyo caso paradigmático sería el Common Sense publicado por Thomas Paine en 1776-, este ejemplo de la historia judía se erigió también en el caso de las revoluciones hispanoamericanas como un tópico central al momento de legitimar religiosamente al gobierno republicano ${ }^{52}$.

Insertándose en esta línea argumental, José Antonio Irisarri realizó la contribución más amplia para el caso chileno. En un registro similar al de Paine, el guatemalteco apeló a la exégesis veterotestamentaria para afirmar la preferencia divina por la república. Según el editor del Semanario Republicano, la idea de que las monarquías eran instituidas por Dios era el fruto de una «aplicación violenta de los textos de la sagrada escritura». Como era de esperarse, el publicista incorporó a la discusión nuevamente el pasaje clave del capítulo VIII del primer libro de Samuel, donde se describía que cuando los israelitas exigieron rey a Yahvé desechando el gobierno colegiado de los jueces -un símil antiguo del gobierno republicano- les fueron anunciadas todas las negativas consecuencias de esta elección. Este pasaje de las Escrituras, agregaba Irisarri, permitía entender claramente que «cuando el Señor no quiso dar reyes a su pueblo escogido, y le hizo la pintura más

52 Sobre la circulación de este modelo en los casos británico y norteamericano, véase Eric NELSON, The Hebrew Republic: Jewish Sources and the Transformation of European Political Thought, Cambridge, 2010. Respecto a sus usos en el mundo hispanoamericano, véase Javier FERNÁNDEZ SEBASTIÁN, Del rey cautivo a la república de derecho divino. Retóricas e imaginarios de las revoluciones bispánicas, en Laura ROJAS y Susan DEEDS (eds.), México a la luz de sus revoluciones, México, 2014, t. 1, pp. 125-185. 
negra de esta clase de tiranos, no pudo manifestar más clara su voluntad contra la monarquía; pero les dio al fin los reyes que pedían, más bien como castigo, que como una felicidad». Así, el análisis del caso de la «república de los hebreos» permitía concluir que las monarquías eran «la maldición del cielo, y que por más que discurra el despotismo para buscar su apoyo en la sagrada escritura, no la podrá lograr jamás, sino adulterando su sentido» ${ }^{53}$.

El análisis del publicista guatemalteco no fue marginal. De hecho, y como era esperable, el uso de la historia bíblica como una cantera de argumentación política para comprobar las inclinaciones o rechazos de la divinidad hacia las formas de gobierno devino en un tópico clave. Camilo Henríquez, por ejemplo, apoyándose en el Antiguo Testamento, pero también en fuentes tan diversas como San Agustín y Cristóbal Suárez de Figueroa, señaló que el linaje de las primeras monarquías, de acuerdo al relato bíblico, no era muy laudatorio para sus defensores: Caín, Nimrod, Cam, «hijo de la maldición de Noé», eran algunos de «los fundamentos de la primera monarquía».

Un análisis de la historia de Israel, por el contrario, demostraba que el diseño institucional adecuado a los preceptos divinos era el republicano. Por eso, ante la pregunta central de este momento: «¿Ha mostrado Dios N. S. predilección y preferencia por alguna forma de gobierno?», el fraile de la Buena Muerte respondía taxativamente: «Puede decirse que el Cielo se ha declarado a favor del sistema republicano: así vemos que éste fue el gobierno que dio a los israelitas». Y profundizando en el tópico de la «república de los hebreos», Henríquez concluía:

Estos fueron gobernados por jueces y por los ancianos del pueblo desde Moisés hasta Samuel, por un espacio de tiempo como de cuatrocientos años. En los últimos días de Samuel el pueblo quiso variar de gobierno y tener un rey como las naciones paganas. Dios le concedió con disgusto un rey, anunciándole el despotismo y servidumbre a que iba a sujetarse, y en que cayó efectivamente ${ }^{54}$.

\section{REFLEXIONES FINALES}

En las páginas precedentes me propuse rescatar la función política del discurso religioso en tiempos de la independencia chilena, tomándolo como una tradición de argumentación que mostró en las vicisitudes del proceso todo su

53 Antonio José de IRISARRI, Sobre el origen y la naturaleza de las monarquías, en El Semanario Republicano, 11 de septiembre de 1813.

54 Camilo HenríQueZ, Catecismo de los patriotas, en El Monitor Araucano, 10 de diciembre de 1813. 
potencial persuasivo. En efecto, al variar el foco de análisis que tiende a circunscribir la historia de la religión al espacio de la historia eclesiástica, o bien desestima la importancia del lenguaje religioso por considerarlo una rémora poco más que anecdótica de una sociedad tradicional destinada a desaparecer, es posible no solamente redescubrir su relevancia como un lenguaje político que, con sus especificidades, incidió en los debates centrales de una época de cambios dramáticos, sino también la heterogeneidad de elementos que confluyeron en la conformación del campo político. Este mismo no poseía la autonomía que la literatura le ha conferido retrospectivamente, sino que se caracterizaba por su yuxtaposición con otros campos, un verdadero «espacio comunicativo» ${ }^{55}$, cuyas fronteras eran porosas, sus demarcaciones flexibles y cambiantes en el tiempo. Así, los traslapes entre política y religión existentes en la época no eran una anomalía, sino una de sus singularidades más evidentes.

La revolución abrió el campo de lo político como un espacio conflictivo y signado por la incertidumbre que tuvo como objeto la definición de las reglas de convivencia en la polis ${ }^{56}$, justamente por la desaparición factual de la figura del Rey. Esto supuso resolver por medio de la discusión un puñado de preguntas políticas cruciales que, de forma inédita en el contexto hispanoamericano, se volvieron objeto de deliberación pública: quién gobierna, en nombre de quién, qué régimen de gobierno es el más adecuado, fueron solo algunas de estas. De manera inevitable, las respuestas a estas interrogantes debían remitir, de una u otra forma, a su validación teológica, no solo porque el auditorio estaba fuertemente cristianizado, sino también porque era claro que el discurso religioso era una cantera prolífica para suministrar argumentos y matices singulares en la articulación de estas reflexiones.

En un sentido más profundo, la religión también proporcionaba sentido. Esto resultaba clave para una sociedad que estaba viviendo la acelerada ruptura de un modus vivendi articulado durante más de tres siglos, pero cuyo horizonte de futuro no se distinguía con claridad. En medio del imperio de lo imprevisible, propio de todo escenario revolucionario, el discurso religioso morigeraba las incertidumbres del proceso y también proveía de un sentido de trascendencia a aquellos cambios proyectados. Aquí, sin embargo, el rol público de la religión fue paradójico. En efecto, no solo tuvo un papel cohesionador en medio del desmo-

55 Willibald STEINMETZ y Heinz-Gerhard HauPT, The Political as Communicative Space in History: The Bielefeld Approach, en Willibald STEINMETZ, Ingrid GILCHER-HolTEY y Heinz-Gerhard Haupt (eds.), Writing Political History Today, Frankfurt, 2013, pp. 21-27.

56 Pierre Rosanvallon, Por una bistoria conceptual de lo político, Buenos Aires, 2003. 
ronamiento súbito de la Monarquía, sino que pese a su carácter transversal, las singularidades del proceso empujaron inevitablemente a la politización de la fe. Por eso, el discurso religioso proveyó consuelo en medio de la angustia y sirvió para cohesionar a la sociedad por medio de la apelación a una fe compartida, pero también se convirtió en un elemento de división.

La guerra iniciada hacia 1813 en el contexto chileno catalizó y profundizó este proceso. En efecto, inserto en una dinámica de radicalización del antagonismo, el discurso religioso pronto se mimetizó con la virulencia que impregnó la discusión pública en aquel momento, acentuando las enemistades al hacerlas tributarias de elementos religiosos. Las condenas morales repetidas ad nauseam en la literatura de la época, que cada actor asignaba al contendor así como se esforzaba por desmentir para sí, dan cuenta de eso: irreligiosos, pecadores, impíos, blasfemos, apóstatas, paganos, cismáticos, herejes, profanos, ateos, libertinos, inmorales. Tales fueron algunos de los epítetos que permiten comprender cómo incluso en el seno de una misma tradición confesional, la religión permitió la conformación de fronteras políticas insalvables.

Una de estas fronteras fue la conformación de identidades políticas incompatibles, como republicanos y monárquicos. Aunque es evidente que el trabajo por delinear las singularidades y las diferencias entre estos regímenes poseía una larga y vasta trayectoria en la historia intelectual, tanto secular como religiosa, por la magnitud del proceso -tanto por la vastedad de los territorios como por la cantidad de países involucrados- las independencias hispanoamericanas fueron un espacio privilegiado para analizar los procesos descritos. Un laboratorio político formidable donde el discurso religioso ensayó una forma de teología política inédita para el continente: un catolicismo republicano. 